ISSN: 0514-7336 — ISSN electrónico: 2386-3943

DOI: https://doi.org/10.14201/zephyrus202086239257

\title{
UN NUEVO CONJUNTO DE MONEDAS EMIRALES DEL CENTRO PENINSULAR: LOS DÍRHAMS DEL YACIMIENTO ARQUEOLÓGICO DE EL REBOLLAR (EL BOALO, MADRID)
}

\section{A new set of Emiral coins from the center of the Iberian Peninsula: dírhams from the archaeological site of El Rebollar (El Boalo, Madrid)}

Javier Salido Domínguez*, Rubén-Lot García Lerga ${ }^{* *}$, Rosario Gómez Osuna ${ }^{* * *}$, Elvira García Aragón ${ }^{* * *}$, Manuel Blanco Domínguez ${ }^{* * * *}$ y Joaquín Barrio Martín*

* Dpto. de Prehistoria y Arqueología. Facultad de Filosofía y Letras. Univ. Autónoma de Madrid. Campus de Cantoblanco. Avda. Tomás y Valiente, 1. Módulo X. 28049 Madrid. Correo-e: javier.salido@uam.es; joaquin. barrio@uam.es. ID ORCID: https://orcid.org/0000-0002-0080-9278; https://orcid.org/0000-0001-5776-0949

** Investigador independiente. Autovía de Extremadura, km 119,400. 45600 Talavera de la Reina (Toledo). Correo-e: rubenlot@yahoo.es. ID ORCID: https://orcid.org/0000-0002-0016-3593

*** A.C. Equipo A de Arqueología. Cl Rubén Dario, 4. 28770 Colmenar Viejo (Madrid). Correo-e: equipoadearqueologia@gmail.com; charogosuna@gmail.com; elvira.garcia.aragon@gmail.com.ID ORCID: https:// orcid.org/0000-0001-5605-0240; https://orcid.org/0000-0002-7752-3980

**** Servicio de Conservación, Restauración y Estudios Científicos del Patrimonio Arqueológico (SECYR). Facultad de Filosofía y Letras. Univ. Autónoma de Madrid. Campus de Cantoblanco. Avda. Tomás y Valiente. Módulo X. 28049 Madrid. Correo-e: manuelm.blanco@uam.es. ID ORCID: https://orcid.org/0000-0002-3367-287x

Recepción: 12/12/19; Revisión: 1/06/2020; Aceptación: 26/11/2020

Resumen: Se da a conocer un pequeńo conjunto de cinco dírhams de época emiral localizado en el interior de la iglesia rural tardoantigua de El Rebollar (El Boalo, Madrid). Este edificio eclesiástico se ha podido fechar a partir de los ajuares funerarios de las tumbas y del análisis de C14 realizado sobre las muestras óseas de los individuos enterrados entre la segunda mitad del s. viI d. C. y comienzos del viII d. C. El conjunto monetario tiene una fecha de cierre que remite al periodo de gobierno de al-Hakam I (180-206 H./796-822 d. C.). El estudio de este lote numismático en su contexto, la lectura sin dificultad de las leyendas que permiten deducir ver variaciones en las monedas y el análisis de su composición, que en este estudio presentamos, ofrecen datos que contribuyen a comprender mejor la producción y la circulación monetaria emiral en el área central de la Península Ibérica.

Palabras clave: Alta Edad Media; etapa emiral; Tardoantigüedad; numismática andalusí; iglesia; al-Ḥakam I.

AвSTRACT: A small set of five dirhams from the Emirate period is presented, located inside the late rural church of El Rebollar (El Boalo, Madrid). This ecclesiastical building can be dated from the grave goods of the tombs and from the $\mathrm{C} 14$ analysis applied to the bone samples from the individuals buried between the second half of the VII ${ }^{\text {th }}$ century and the beginning of the viII ${ }^{\text {th }}$ century. The coins have a closing date that refers to the period of government of al-Hakam I (180-206 H./AD 796-822). The study of this numismatic set in its context, the reading without difficulty of the legends which allow us to deduce variations in the coins and the analysis of 
their composition, which we present in this study, provide data which contribute to a better understanding of the production and circulation of emerald money in the central area of the Iberian Peninsula.

Key words: Early Middle Ages; Emiral period; Late Antiquity; Andalusian numismatics; church; al-Hakam I.

\section{El yacimiento de El Rebollar ${ }^{1}$}

El yacimiento se halla en el cerrillo de El Rebollar, ubicado en un terreno municipal a $1,5 \mathrm{~km}$ al sureste de la localidad de El Boalo, que corresponde administrativamente al término municipal de El Boalo, Cerceda y Mataelpino, en el no de la Comunidad de Madrid (Fig. 1). Este cerrillo se eleva a una cota máxima de $1000 \mathrm{~m}$ y está situado entre dos de los principales dominios geológicos de la Península Ibérica: el Sistema Central y la Cuenca del Tajo, más concretamente, en las estribaciones centrales del Sistema Central. Se trata de una cadena montañosa, de dirección NE-SO, integrada por numerosas alineaciones como la Sierra de Guadarrama y pequeños valles fluviales intercalados (Fig. 2). Se halla en la comarca de la Cuenca del Guadarrama, a pesar de que ninguno de sus cursos fluviales vierte en este río. Todos sus riachuelos y arroyos son afluentes o subafluentes del Manzanares, en cuya cuenca hidrográfica se encuentra integrado todo el término.

El paisaje se halla muy compartido por las estribaciones serranas, siendo desde antiguo un lugar de paso y de comunicaciones entre ambas mesetas, lo que explica la densa red de cañadas, veredas, cordeles y coladas existentes. El yacimiento arqueológico se ubica en un pequeño cerro estratégicamente situado sobre la vía de comunicación que, por el pie de sierra, discurre a poca distancia del yacimiento y que pasó a denominarse 'Cañada Real Segoviana' en la Edad Media. Se trata de un espacio dominado por los materiales graníticos, con aportes arenosos de los arroyos del Cerrillo, del Herrero y

\footnotetext{
1 Este trabajo se enmarca en la línea de investigación del Proyecto de Transferencia Arqueología en Comunidad para la Sierra de Madrid: excavaciones de la Ermita de la Virgen del Sacedal, dirigido por J. Salido, y que ha permitido la firma de un convenio -n. ${ }^{\circ}$ 0620/2019- entre el municipio de El Boalo, Cerceda y Mataelpino y la Fundación de la Univ. Autónoma de Madrid. Los directores de la excavación arqueológica son J. Salido -UAM- y R. Gómez Osuna -Equipo A de Arqueología-.
}

de Campuzano, que desaguan en el arroyo Samburiel. El arroyo de los Herreros pasa a pocos metros del cerro, bordeando sus flancos NE y E. Poco más al s, cerca de la esquina SE del cerro, se une con el arroyo del Cerrillo.

Teniendo como base la información aportada por los geólogos M. Segura-UAH- y F. Bellido -IGME-, que han colaborado en la campaña de 2019, el yacimiento se asienta sobre un afloramiento de pegmatitas con un filón de feldespato en el cerro, una roca que favorece su aprovechamiento como base por su solidez y, a la vez, fácil fractura por sus cristales gruesos y numerosas vetas. Los materiales de las diferentes sepulturas, tanto sarcófagos como lajas, corresponden a granitos del tipo Alpedrete, de grano medio, por tanto, facies locales con ligeras variaciones entre sí. Asimismo, se reconocen calizas procedentes de Cerceda, zonas de extracción muy próximas al yacimiento ${ }^{2}$.

\section{Historia de las investigaciones}

Las primeras noticias del yacimiento se remontan a 1953 y a los trabajos de documentación realizados por la Dirección General de Bellas Artes en 1967 que constatan la presencia de tres tumbas con cubiertas de granito orientadas de $\mathrm{E}$ a o. En el interior de una sepultura, se localizó un olpe de boca trilobulada, panzudo y asa vertical, fabricado a mano, con pasta rojiza y mucha mica, completo y cubierto de una fuerte capa de barro, así como algunos restos óseos ${ }^{3}$.

2 En la campaña arqueológica de 2020 se ha sumado al proyecto el equipo de geólogos integrado por los profesores M. Gómez Heras y B. Oliva Urcia, del Dpto. de Geología y Geoquímica de la UAM.

3 Viñas, V.: Prospección realizada en 'Peña Sacra', término de El Boalo, provincia de Madrid. Informe inédito depositado en 1967 en la Escuela de Formación Profesional de Restauración del Casón del Buen Retiro, Madrid. 


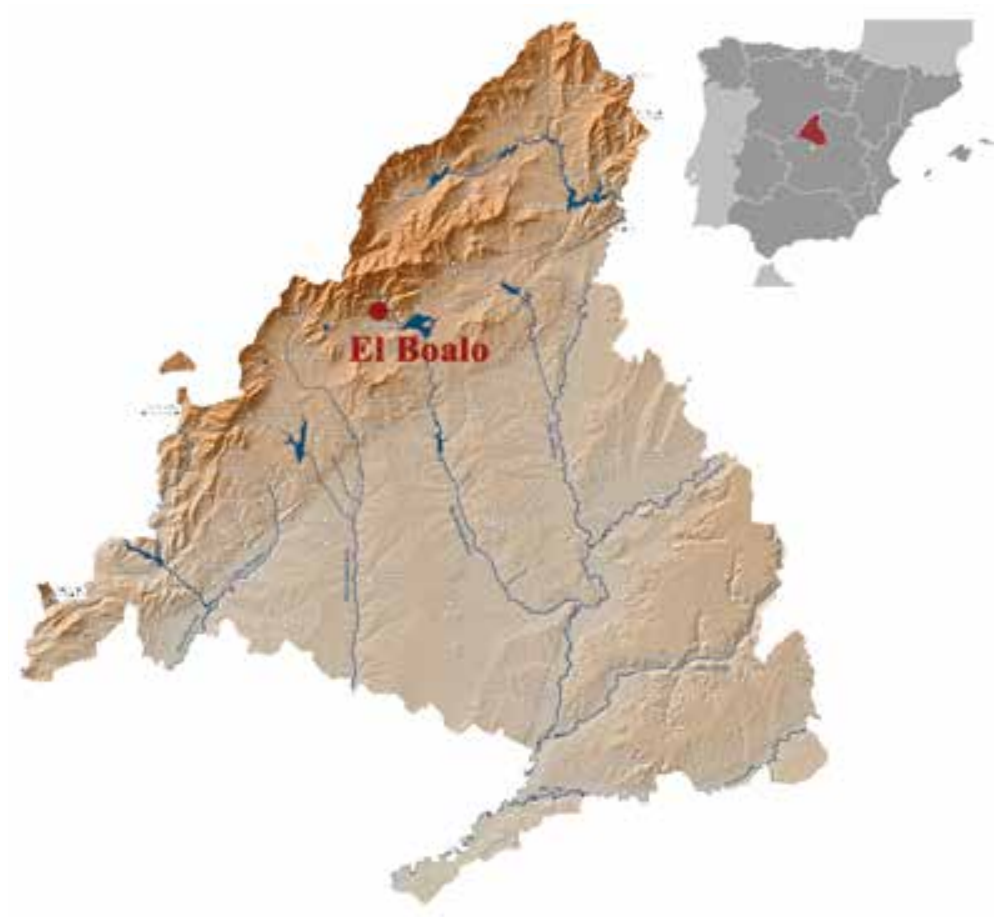

Fig. 1. Localización de El Boalo en la Comunidad de Madrid.

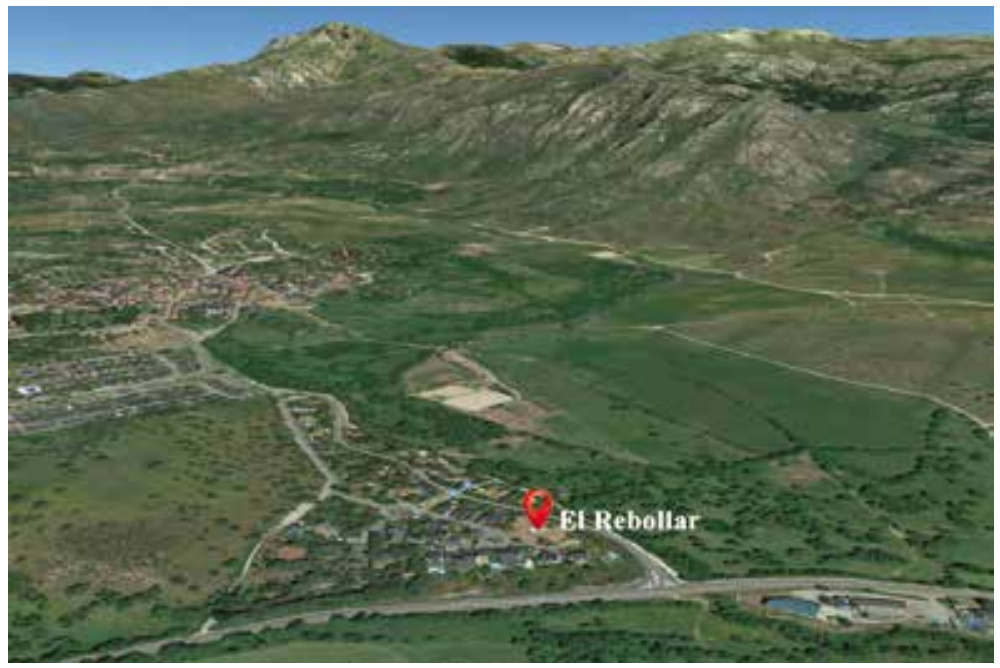

Fig. 2. Ubicación del yacimiento de El Rebollar en El Boalo (Madrid) y el centro del municipio (a partir de Google Maps). y $\mathrm{Olmo}^{4}$, delimitó la zona que debía conservarse para su futuro estudio $y$ confirmó su cronología altomedieval.

A partir de esta información, el yacimiento de El Rebollar en El Boalo se plantea como una necrópolis altomedieval que podría formar parte de la red de asentamientos de tipo aldeano, como los yacimientos localizados en Navalvillar y Navalahija (Abad, 2006; Colmenarejo y Rovira, 2006; Colmenarejo, 2009; Colmenarejo et al., 2016), y la necrópolis de Remedios, en Colmenar Viejo (Colmenarejo et al., 2005); El Cancho del Confesionario, en Manzanares El Real (Caballero y Megías, 1977), y la aldea y necrópolis de La Cabilda, en Hoyo de Manzanares (Gómez Osuna et al., 2016, 2018), que evidencian un modelo de gestión del espacio que complementa la actividad agropecuaria con actividades artesanales como la minería y la cantería (Aracil et al., 2016).

Respecto al mundo funerario y religioso, directamente relacionado con la actuación arqueológica realizada, destacan las excavaciones arqueológicas practicadas en la necrópolis de Remedios, desarrolladas durante cinco campañas entre 1999 y 2009. Los resultados finales concluyen en la selección de este lugar como posible centro cultual de las primeras comunidades rurales cristianas en el centro de la actual comunidad madrileña, estableciéndose un amplio lapso cronológico que transcurre prácticamente desde época visigoda hasta la actualidad. La tipología de sepulturas es muy similar a la documentada en El Rebollar, como
Durante las décadas siguientes el yacimiento fue objeto de excavaciones clandestinas que afectaron a un buen número de sepulturas. La actuación arqueológica parcial de 1998, dirigida por Castro
4 Castro, M. y Olmo, L. (1998): Proyecto y Memoria de Actuación arqueológica. Necrópolis del cerro del Rebollar, El Boalo, abril y junio de 1998. Informe inédito depositado en 1998 en la Consejería de Educación y Cultura, Comunidad de Madrid. 
ya señalan Castro y Olmo5 . En la Sierra de Madrid se han localizado también enterramientos similares a los documentados en El Rebollar en diferentes espacios funerarios no asociados a centros de culto ${ }^{6}$, pero también en el interior de iglesias tardoantiguas como la de Valcamino ${ }^{7}$, en El Berrueco, y la del cerro de San Babilés, en Boadilla del Monte (Sanguino y Ońate, 2016).

Los trabajos arqueológicos, desarrollados durante las tres campañas de 2018, 2019 y 2020, han permitido localizar una iglesia rural de época tardoantigua, aún en proceso de estudio, asociada a la necrópolis ya documentada. La campaña realizada en 2018 partía de la hipótesis de que una pequeña iglesia dio cobertura espiritual a esos enterramientos y de que pudo continuar posteriormente como ermita tras el abandono del lugar. La documentación de archivo del s. XviII informa sobre la presencia de un lugar de culto dedicado a la Virgen de El Sacedal que podría corresponder con esta edificación ${ }^{8}$.

\section{La fase altomedieval del yacimiento del cerrillo de El Rebollar (El Boalo, Madrid)}

El edificio de culto localizado está constituido por un aula rectangular de nave única de

5 Castro y Olmo, op. cit. n. 4.

6 García Aragón, E. (2013): Estudio de los enterramientos tardoantiguos y alto-plenomedievales de la Cuenca Alta del rio Manzanares. Trabajo de Fin de Máster inédito presentado en 2013 en la Univ. Autónoma de Madrid.

7 Mendoza, M. J. y Cano, J. J. (2020): "La iglesia tardoantigua de Santa María de Valcamino, El Berrueco (Madrid)". En Salido, J. y Gómez, R. (eds.): Iglesias tardoantiguas en el centro peninsular (siglos V-VIII d. C.). Arqueología y Arquitectura. Madrid, en prensa.

8 En diversos libros que dan cuenta de visitas eclesiásticas, conservados en el Archivo Diocesano de Madrid, se hace mención al lugar como "... El Prado de la Cańadilla, propio de la Virgen del Sacedal..." (Archivo Diocesano de Madrid, signatura 202920). De nuevo en la Visita eclesiástica de 1755 se alude a la Virgen de El Sacedal (Archivo Diocesano de Madrid, signatura 202920), mientras que en la Visita eclesiástica de 1757 se refiere a una zona ya como "Prado del Sazedal" (Archivo Diocesano de Madrid, signatura 202920) y en la Visita eclesiástica de 1761 como "Tierra del Saferal y saceral”, también en la Visita eclesiástica de 1764 como Zerca del Sazeral. Como "tierra de Sacezal" aparece en las Visitas eclesiásticas de 1772 y 1787. aproximadamente $13 \times 7 \mathrm{~m}$ y rematada en un ábside o cabecera de planta cuadrada orientada al E (Fig. 3) que, en su fase final, mide $5 \times 4,1 \mathrm{~m}$. Además, cuenta con una estancia anexa al $\mathrm{N}$, comunicada con un acceso y otro espacio conectado a los pies'. En la campaña arqueológica de 2020 hemos continuado la excavación al o, donde se ha podido documentar una ampliación que duplica la extensión del edificio, ahora en proceso de estudio, que se enmarca en una reforma constructiva de mayor calado durante el periodo bajomedieval.

En el interior de la nave se han localizado 12 tumbas perfectamente orientadas en el sentido de la nave y alineadas con los muros perimetrales. Se ordenan en cuatro hileras, incluyendo tumbas de individuos infantiles y adultos. La Tumba 1 localizada en la campaña de 2018 ha sido datada por $\mathrm{C}^{14}$ en la segunda mitad del s. viI d. C. e inicios del viII d. C., fecha que se inscribe en el periodo de construcción y primer uso religioso del edificio. Se trata de una tumba de cista, cuyos restos óseos de un individuo adulto se hallaban en un impecable estado de preservación ${ }^{10}$. Esta información se ve corroborada por los resultados de $\mathrm{C}^{14}$ realizados a partir de las muestras de los restos óseos de otras tumbas del interior de la nave, así como por los materiales que conforman el ajuar funerario ${ }^{11}$.

En la Tumba n. ${ }^{\circ}$, se depositaron dos individuos, fechados por $\mathrm{C}^{14}$ en 656-725 d. C. -calibración 2s, 95\% probabilidad- el individuo extendido a lo largo del sarcófago y entre 669-778 d. C. -calibración 2s, $95 \%$ probabilidad- el adulto situado

9 Salido, J.; Gómez, C. y García, E.: “El yacimiento del Cerro de El Rebollar, El Boalo. Intervenciones arqueológicas de los años 2018-2019”. En Actas de la reunión de Arqueología Madrileña 2019. Alcalá de Henares: Colegio de Arqueólogos de Madrid y Dir. Gral. de Patrimonio de la Comunidad de Madrid, en prensa.

10 El estudio antropológico de los restos localizados en el yacimiento está siendo realizado por el equipo dirigido por Dres. A. González Martín y O. Cambra Moo, profesores del Dpto. de Biología de la UAM.

11 Salido, J.; Gómez, C. y García, E.: "La iglesia tardoantigua de El Rebollar (El Boalo, Madrid). Resultados preliminares de las campañas arqueológicas de 2018-2020". En Salido, J. y Gómez, R. (eds.): Iglesias Tardoantiguas en el centro peninsular (siglos V-VIII d. C.). Arqueología y Arquitectura. Madrid, en prensa. 


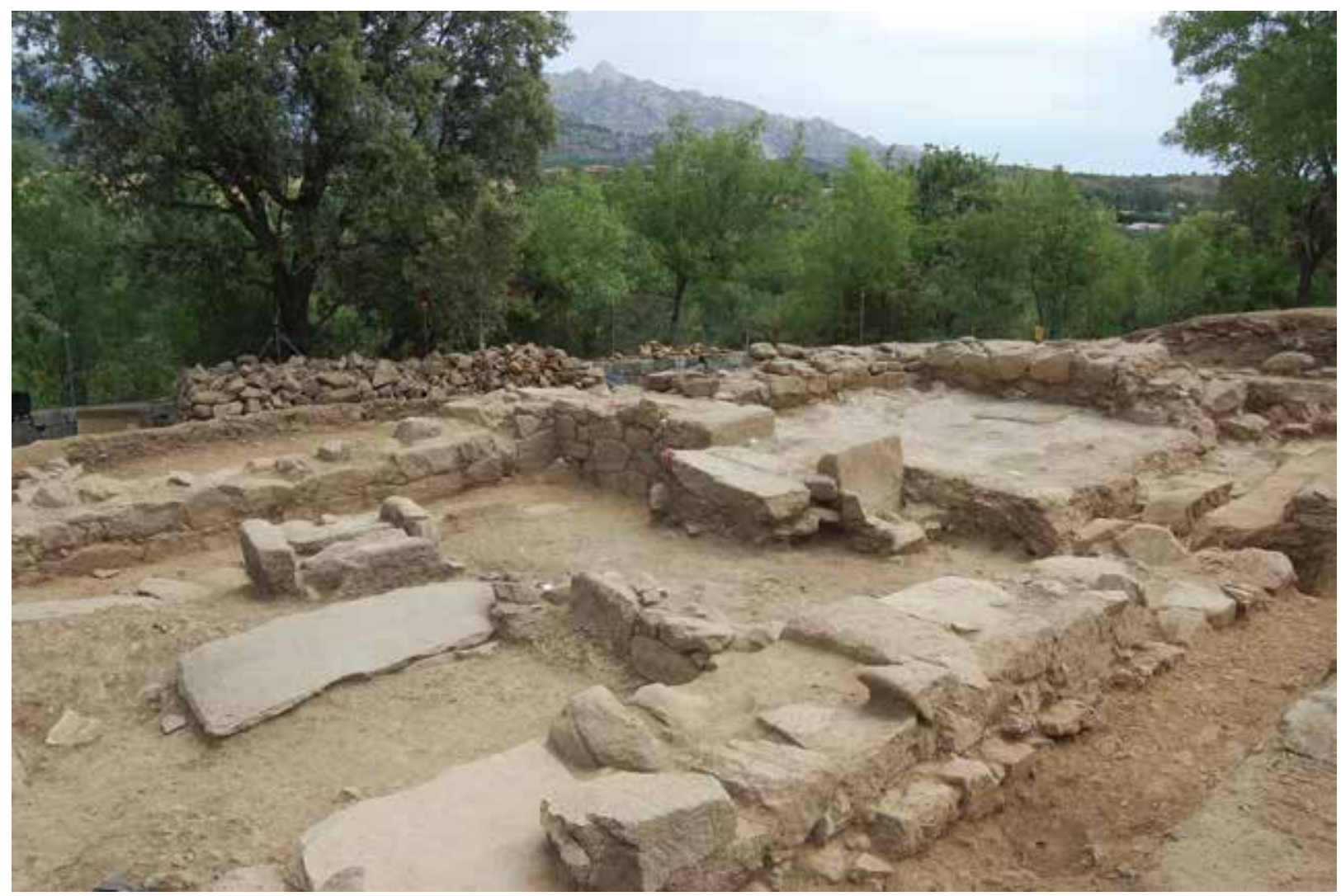

FIG. 3. Estado de conservación del yacimiento al finalizar la campaña de 2019.

a los pies del anterior. El primero está asociado a una botella -n. ${ }^{\circ}$ inv. 2019/20/308-, de base ligeramente convexa, cuerpo cilíndrico, cuello estrecho, con dos asas de cinta de sección romboidal. De factura tosca, es asimétrica y presenta una altura de $27 \mathrm{~cm}$. Este tipo cerámico correspondiente a la forma т.15.5, según la tipología de Gutiérrez Lloret (1996), se ha podido datar en contextos del centro peninsular del s. vi d. C. y, sobre todo, del viI d. C., como en la parcela R3 de la Vega Baja, en Toledo (Aranda, 2013: 393, figs. 7-9); en Camino de los Afligidos, Alcalá de Henares (Fernández Galiano, 1976, fig. 33; Méndez y Rascón,1989: fig. 64, n. ${ }^{\circ}$ 1); en el Cerro de las Losas en El Espartal, Madrid (Alonso, 1976: fig. 13), y en Castiltierra, Segovia (Camps, 1984: fig. 73). Este tipo de recipientes se han fechado también en contextos en los ss. VI-VII d. C. en Pla de Nadal, Valencia (Juan y Centelles, 1985), en La Alcudia de Elche (Gisbert, 1986: figs.
1-3), y en el Tolmo de Minateda (Gutiérrez Lloret, 1996: 108, fig. 37). El ajuar de la Tumba n. ${ }^{\circ} 6$ está formado por dos anillos de aro filiforme, dotados de chatones decorados, ahora en estudio, asociados a un enterramiento fechado por $\mathrm{C}^{14}$ en 662-731 d. C. - calibración 2s, 95\% probabilidad-.

Hasta el momento se han localizado en el interior de la iglesia tardoantigua 12 tumbas, situadas a diferentes cotas de profundidad, siendo más profundas en la mitad septentrional de la nave - cubierta de la Tumba n. ${ }^{\circ} 4$ a 2,90 m- que en la meridional -cubierta de la Tumba n. 1 a 2,70 m-, pues el suelo de la nave se hallaba ligeramente inclinado hacia el $\mathrm{N}$. En la hilera septentrional se han documentado, de o-E, las tumbas n. ${ }^{\text {os }} 11,4,2,7,8$ y 9; en la hilera central, las tumbas n. ${ }^{\text {os }} 3,6$ y 15 , y, en la meridional, las n. ${ }^{\text {os }} 1,5$ y 10 . Entre la hilera central y la meridional hemos localizado durante la campaña 2020 otra tumba -n. ${ }^{\circ} 16-$, justo al s de la 
n. ${ }^{\circ}$ 6, y marca el nivel más profundo que nos interesa para el estudio de las monedas.

\section{El depósito monetario de El Rebollar (El Boalo)}

\subsection{Contexto arqueológico del depósito monetario}

La secuencia estratigráfica de la nave de la iglesia se ha podido analizar en su conjunto al finalizar la campaña arqueológica de 2020. En el área donde se localizó el depósito monetario, durante esta última actuación, hemos localizado la Tumba 16, formada por tres losas coberteras -UE 2118-, que se hallan a 2,88 $\mathrm{m}$ de profundidad. Sobre estas localizamos un nivel de cascajo -UE 2011-, formado por piedras fragmentadas compactadas, que se empleó para ocultar las tumbas y como pavimento de la iglesia tardoantigua. En esta UE, comprendida entre 2,88 y
2,50 $\mathrm{m}$ de profundidad, localizamos escaso material cerámico, cuatro fragmentos de cerámica común de galbos muy rodados -2018/39/330 - que no aportan datación.

Es en la cota de profundidad más alta de este nivel donde se localizó el conjunto de cinco dírhams situados todos a la misma cota $-2,52 \mathrm{~m}-$. Las monedas se hallaron muy próximas entre sí y dos de ellas -2018/39/66 y 2018/39/67; n. ${ }^{\text {os }} 1$ y 2 - aparecieron adheridas (Figs. 4 y 5). No existía una estructura negativa que rompiera la unidad estratigráfica, lo que justificaría una posible ocultación. Tampoco se hallaron asociados a las monedas restos de un recipiente cerámico, de modo que, de hallarse en el interior de algún contenedor, este tendría que haber sido confeccionado con algún tipo de material orgánico, como tela o cuero, del que no se ha conservado ningún fragmento. La proximidad entre las cinco monedas y el hecho de que aparezcan en posición

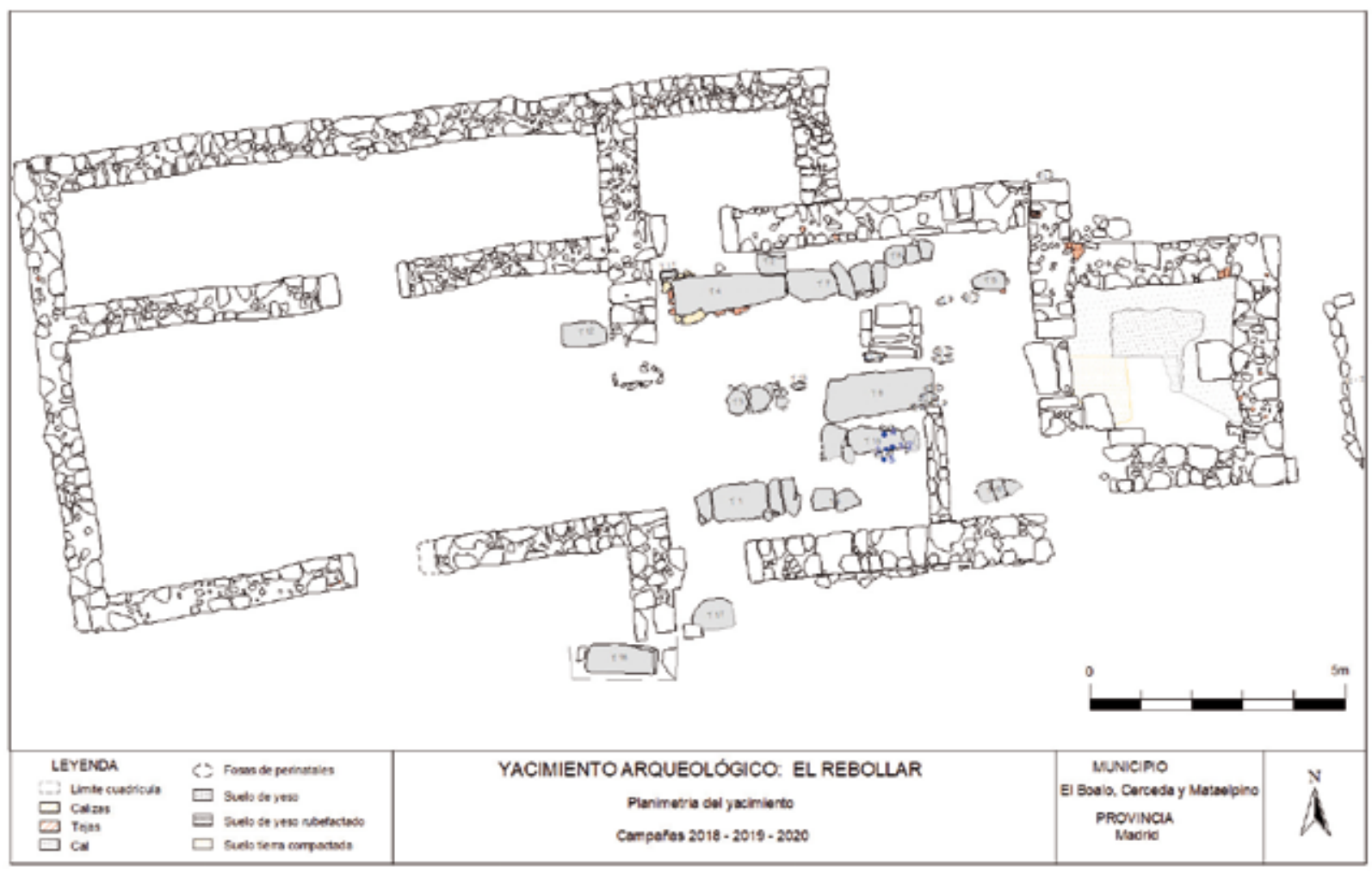

Fig. 4. Planta del edificio excavado en las campañas arqueológicas de 2018-2020, con indicación del lugar de hallazgo de los dírhams emirales. 


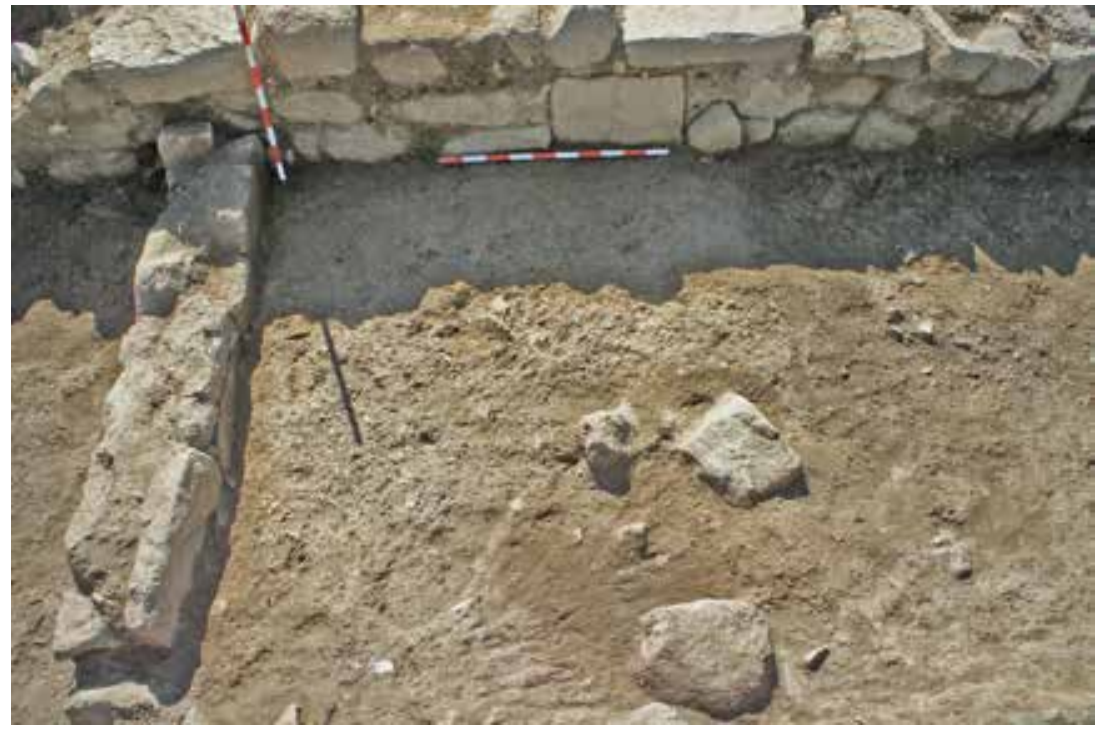

FIG. 5. Nave de la iglesia tardoantigua $=U E 2011$.

202 H./810-818 d. C., de modo que el depósito se encuadra en el gobierno de al-Hakam I, el tercer emir independiente de Córdoba. Aunque es un conjunto poco voluminoso, proporciona una información numismática e histórica significativa, dada su singularidad, su fácil lectura, el excelente estado de conservación y el hecho de que se trate de monedas poco frecuentes en el centro peninsular.

Respecto a las características formales de las piezas de El Boalo (Figs. 6 y 7) puede afirmarse que presentan la clásica distribución de leyendas de la moneda de plata omeya, que se mantiene vertical y dos perfectamente adheridas podrían ser indicios de que pudieron contenerse en un saquito, pero no tenemos más argumentos para defender esta hipótesis.

Sobre este nivel documentamos la UE 2004, con cota inicial de 2,21 m y final de 2,50 m de profundidad, que corresponde al abandono progresivo de la iglesia. Presenta una gran acumulación de piedras, algunas de gran volumen y numerosos restos de tejas. No cabe duda de que el propio derrumbe afectó al nivel inferior. En las cotas más altas dentro de la UE 2004 localizamos piezas del periodo bajomedieval ${ }^{12}$.

\subsection{Las monedas}

Los dirhams localizados en El Rebollar, El Boalo, presentan una cronología comprendida entre 195 y

12 Este material se halla en el nivel de derrumbe y no permite fechar el periodo de la deposición de las monedas. Al periodo bajomedieval corresponden varios enterramientos infantiles realizados en la zona de la nave más próxima a la cabecera. Dos de estos individuos infantiles contaban con una moneda de época de Juan II de Castilla entre las manos que fechan dichos enterramientos en la primera mitad del s. Xv. Agradecemos a I. Centeno Cea el análisis preliminar de la cerámica de estas UUEE, que está realizando en detalle en estos momentos. durante todo el periodo emiral sin apenas variaciones, con el año de acuñación como único elemento diferenciador ${ }^{13}$. Para su catalogación hemos optado tanto por ofrecer las referencias al tipo general de Vives (1893) como a la obra más reciente de Frochoso (2009), que permite mayor precisión al incluir nuevas variantes.

Para la Moneda 1 (Vives 95; Frochoso 195.12) destaca la presencia de círculos con punto interior que se intercalan entre las gráfilas exteriores de anverso. En reverso este dirham solo presenta un punto

$13 \mathrm{Al}$ igual que toda la plata acuñada en este periodo, las monedas de El Boalo presentan en el centro del anverso una leyenda central en tres líneas con la profesión de fe musulmana: "No hay más Divinidad que / Dios, Único / no tiene asociado". Alrededor contienen una leyenda marginal con la referencia de ceca y fecha: "En el nombre de Dios fue acuñado este dírham en al-Andalus en el año (año de acuńación)". En el centro del reverso se aprecia una leyenda central en cuatro líneas con los versículos 1 al 4 de la Sura 112 del Corán: "Dios es Uno, Dios / es eterno. No ha engendrado / ni ha sido engendrado. No tiene / semejante a Él" y, alrededor, una leyenda marginal con el versículo 9 de la Sura 61 del Corán: "Mahoma enviado de Dios, le envió con la dirección y la religión verdadera para que prevalezca sobre toda otra religión a despecho de los asociadores" (Medina, 1992: 78-82). 
sobre la leyenda central y tres puntos formando un triángulo bajo la misma.

En la Moneda 2 (Vives 99; Frochoso 196.11) podemos observar una media luna o arquito invertido entre la segunda y la tercera línea de la leyenda central de anverso. Alrededor presenta gráfila exterior con círculos con punto interior que se intercalan entre las mismas. En el reverso se incluye un punto central sobre la leyenda central de reverso

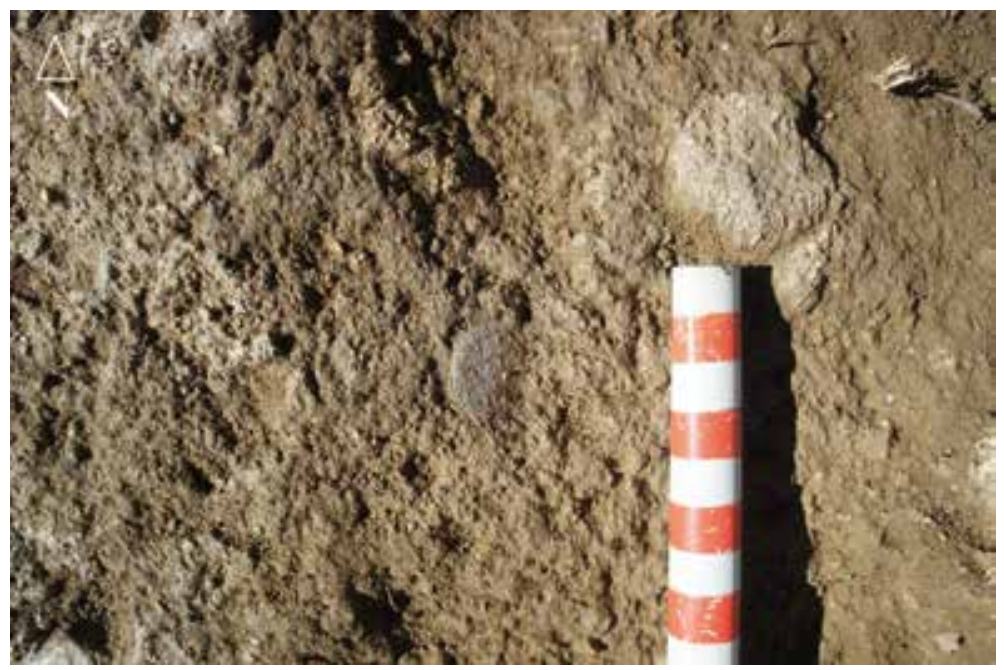

FIG. 6. Disposición de las dos monedas adheridas entre sí (n. ${ }^{\text {os }} 1$ y 2 ).

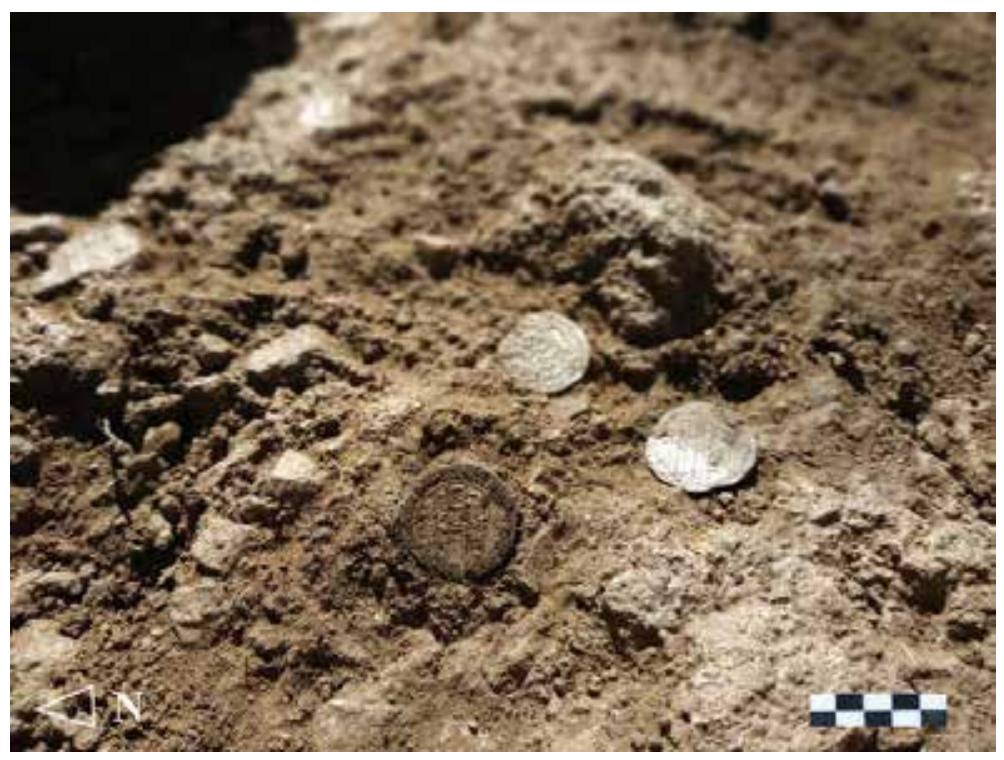

Fig. 7. Posición in situ de los numismas en la UE 2011. y entre la segunda y la tercera línea, así como tres puntos formando un triángulo por debajo de la leyenda central.

La Moneda 3 (Vives 101; Frochoso 197.8) contiene una estrella entre la segunda y la tercera línea de la leyenda central de anverso. Al exterior, podemos encontrar círculos con punto interior que se intercalan entre las gráfilas exteriores de anverso. En el reverso se observa un punto entre la segunda y la tercera línea, así como una media luna que se une a la gráfila que separa la leyenda central de la marginal por encima de la leyenda central y bajo la misma.

En la Moneda 4 (Vives 106; Frochoso 199.8) podemos apreciar un símbolo entre la segunda y la tercera línea de la leyenda central de anverso que Frochoso (2009: 61) identifica como una marca del grabador de la pieza. También hay que destacar la decoración de círculos con punto interior que se alternan con otras de tres puntos formando un triángulo que se intercalan entre las gráfilas exteriores. En el reverso se repiten los mismos elementos descritos para el dírham 2.

Finalmente, la Moneda 5 (Vives 114 variante; Frochoso 202 variante) permite observar que el numeral de la fecha presenta un fallo de escritura, ya que le falta el alif inicial. Desconocemos si esta falta de ortografía responde a un despiste por parte del abridor de cuño, a un deficiente conocimiento de la escritura árabe o, más probablemente, a una variante dialectal muy común en diferentes regiones de influencia árabe en la que figura la escritura del numeral 'dos' sin la alifinicial, adquiriendo la forma tantayn (Peña y Vega, 2007: 161 y 171). También de esta pieza hay que reseńar que se trata de un ejemplar cuya variante no se encuentra 
recogida ni en el catálogo de Vives (1893: 13) ni en el reciente estudio sobre el dirham emiral realizado por Frochoso (2009: 137), al presentar arquito con punto interior y no arquito invertido con punto interior como suele ser habitual en las monedas de este ańo -tipos Frochoso 202.3, 202,4, 202.5 y 202.6-. Para el reverso, sobre la leyenda central sí observamos el típico arquito invertido que también podemos apreciar en otros ejemplares del 202 H./817-818 d. C. -tipos Frochoso 202.2 y $202.4-$.

\section{Análisis de la composición de las monedas}

Durante la fase de estudios previos en la intervención de restauración de los cinco dírhams se han realizado distintos microanálisis elementales sobre la superficie de las Monedas 1, de 195 H., y 5, de 202 H., con el objetivo de determinar la pureza de la plata e identificar sus pátinas y depósitos superficiales, como apoyo a los posteriores tratamientos de limpieza y protección llevados a cabo en el SECYr en la campaña de 2019 por la Dra. M. ${ }^{a}$ C. Medina ${ }^{14}$.

El equipo utilizado pertenece al Laboratorio de Microscopía Electrónica de Barrido y Análisis por Energía Dispersiva de Rayos x del Servicio Interdepartamental de Investigación de la UAM -SIdI-. Es importante señalar que, con este mismo equipo de Microscopía y la misma técnica, E. Salvador, se realizó el análisis de la serie más larga de dírhams emirales publicada hasta la fecha, la del Museo Casa de la Moneda, ajustando la técnica general eDx para la cuantificación más precisa de la relación $\mathrm{Ag} / \mathrm{Cu}$, ya que esta es la base de referencia para la Ley de las Monedas de plata (Salvador y Canto, 2004: 117-119). Los resultados que se valoran a continuación corresponden a dos microanálisis, uno en cada moneda,

14 Los trabajos de restauración de las monedas fueron realizados en el Servicio de Conservación, Restauración y Estudios Científicos del Patrimonio Arqueológico (SECYR) de la UAM, bajo la dirección de J. Barrio, y financiados por la Dir. Gral. de Patrimonio Cultural de la Comunidad de Madrid. que se tomaron en áreas de aproximadamente 0,5 $\mathrm{mm}^{2}$ en la zona más clara y limpia de su superficie.

Los análisis muestran que ambos dirhams presentan un elevado contenido en plata, ligeramente inferior en el caso de la Moneda 1, donde también se ha detectado la presencia de cobre, aproximadamente en una proporción $98 \% \mathrm{Ag}-2 \% \mathrm{Cu}$. Estos contenidos en plata son discretamente superiores a los valores medios de los dirhams de sus años de acuñación, recogidos en los escasos trabajos que publican series analíticas de época emiral, que se sitúan en el intervalo 90-95\% (Canto, 1994: 132; Fernández et al., 2001: 566-567). Sin embargo, cuando se revisan en detalle los datos obtenidos en los ejemplares de la Colección del Museo Casa de la Moneda emitidos por al-Hakam I entre el 195 y 202, intervalo en que se sitúa la serie de El Rebollar, nos encontramos en varios años en que hay resultados entre el 95 y el $98 \%$, con una media para el año 199 del 97\%. No obstante, la media general en estas emisiones emirales sería la indicada (Canto e Ibrāhīm, 2004: 41-43). Como sucede en todas las fundiciones preindustriales los valores cuantificables pueden sufrir variaciones perfectamente justificables.

En este sentido, también deberían tenerse en cuenta otras razones para explicar esta diferencia en porcentaje de dirhams analizados en el presente estudio. Este incremento en el contenido en plata de las monedas de El Rebollar respecto a los estudios de referencia obedece probablemente a dos causas principales. Por un lado, a los procesos de corrosión diferencial y lixiviado de los productos de alteración del cobre que ha podido sufrir la superficie de las piezas de este yacimiento durante el enterramiento, con su consiguiente enriquecimiento en $\mathrm{Ag}$ y en detrimento de su contenido en $\mathrm{Cu}$. Por otro lado, y sin entrar en detalles, puede deberse tanto a la calidad -un excelente estado de conservación sin corrosión diferencial previa- de los ejemplares analizados en las colecciones de los estudios de referencia, caso de las piezas del Museo Casa de la Moneda, como a la mayor exactitud de su método de medida -mayor superficie de análisis y mayor número de medidas; 


\begin{tabular}{|c|c|c|c|c|c|c|c|c|c|}
\hline N.o & UE & $\begin{array}{c}\text { N.o } \\
\text { inventario }\end{array}$ & $\begin{array}{l}\text { Peso ante } \\
\text { restauración } \\
\quad(\mathrm{g})\end{array}$ & $\begin{array}{c}\text { Peso post } \\
\text { restauración (g) }\end{array}$ & $\begin{array}{l}\text { Módulo } \\
(\mathrm{mm})\end{array}$ & $\begin{array}{c}\text { Eje de } \\
\text { cuños (h) }\end{array}$ & Ceca & $\begin{array}{c}\text { Ref. } \\
\text { Vives/ } \\
\text { Frochoso }\end{array}$ & Datación \\
\hline 1 & 2011 & $2018 / 39 / 66$ & 2,44 & 2,44 & 25 & 8 & al-Andalus & $\begin{array}{c}\text { V-95/FRO- } \\
195.12\end{array}$ & $\begin{array}{l}195 \text { H./810- } \\
811 \text { d. C. }\end{array}$ \\
\hline 2 & 2011 & $2018 / 39 / 67$ & 2,66 & 2,68 & 26 & 5 & al-Andalus & $\begin{array}{c}\text { V-99/FRO- } \\
196.11\end{array}$ & $\begin{array}{c}196 \text { H./811-812 } \\
\text { d. C. }\end{array}$ \\
\hline 3 & 2011 & $2018 / 39 / 69$ & 2,12 & 2,13 & 24 & 6 & al-Andalus & $\begin{array}{c}\text { V-101/FRO- } \\
197.8\end{array}$ & $\begin{array}{c}197 \text { H./812-813 } \\
\text { d. C. }\end{array}$ \\
\hline 4 & 2011 & $2018 / 39 / 68$ & 2,36 & 2,35 & 25 & 7 & al-Andalus & $\begin{array}{c}\text { V-106/FRO- } \\
199.8 \\
\end{array}$ & $\begin{array}{c}199 \text { н./814-815 } \\
\text { d. C. }\end{array}$ \\
\hline 5 & 2011 & $2018 / 39 / 70$ & 2,51 & 2,51 & 27 & 7 & al-Andalus & $\begin{array}{l}\text { v-114 vte./ } \\
\text { FRO- } 202 \text { vte. }\end{array}$ & \begin{tabular}{|c|}
202 н./ $/ 817-818$ \\
d. C.
\end{tabular} \\
\hline
\end{tabular}

FIG. 8. Monedas del conjunto de El Boalo ordenadas según la cronología de acuñación.

valores corregidos con patrones de calibración; etc.-, a pesar de haber utilizado la misma técnica de análisis y equipo -SIdI-UAM-.

Para el periodo concreto que nos ocupa hay que recordar que en el volumen de producción en los años finales del gobierno de al-Hakam I, especialmente desde el $202 \mathrm{H}$. (817 d. C.), se produjo un marcado descenso tanto en la emisión de dirhams como en el peso, que ahora se sitúa entre 2,56-2,65 g (Castro, 2000: 173). Los ejemplares de El Rebollar tienen un peso medio de $2,4 \mathrm{~g}$, marcadamente inferior al peso teórico de un dirham sin alteraciones, estimado entre 2,65 y 2,70 g (Canto y Marsal, 1986). Este descenso puede explicarse por la existencia de un modelo de pagos dual al Estado, uno con moneda como valor de cuenta y otro con moneda al peso para los grandes pagos estatales (García Lerga, 2017: 29-37).

\section{El depósito monetario de El Rebollar en el contexto peninsular}

Los dirhams recuperados presentan una cronología comprendida entre 195 y 202 H./810-818 d. C. De acuerdo con la caracterización de hallazgos monetarios de cronología emiral documentados en la Península Ibérica realizada por Martín Escudero (2015), el conjunto de monedas recuperadas en la iglesia de El Rebollar se encuadra en los denominados 'hallazgos de la primera época', que engloba los depósitos ocultos entre los gobiernos de 'Abd al-Rahmān I y al-Hakam I (Martín Escudero, 2015: 178).
Los hallazgos de la primera época, que, al igual que el conjunto de El Rebollar, presentan fechas de cierre en el gobierno de al-Hakam I (180-206 H./796-822 d. C.), corresponden a los conjuntos de Córdoba depositados en el man (Canto, 1988: 147-162), Córdoba-c/ Doce de Octubre (Marcos y Vicent, 1993: 210-211; Canto, 2007a: 18) ${ }^{15}$, Antequera (Málaga) (Gozalbes y Ayala, 1995-1996: 235-242), Pinos Puente (Granada) (Martín Escudero, 2011: 121-123), La Alcornocosa (Villaviciosa de Córdoba) (Alfaro Asíns, 1993: 48; Marcos y Vicent, 1993: 194-197; Peña y Vega, 2007: $147-$ 202; Canto, 2007a: 18-20, entre otros), Burriana (Castellón) (Doménech, 2003: 118-120) ${ }^{16}$, Mérida-Teatro Romano (Badajoz) (Segovia y Velázquez, 2011: 795-816), Cerro de la Almagra (Mula, Murcia) (González y Fernández, 2018: 81-119) y el

15 Las 386 monedas que conforman este conjunto están pendientes de restauración, por lo que no ha podido ser clasificado en su totalidad. Así pues, su datación debe ser considerada como provisional a la espera de una completa catalogación de los ejemplares que lo componen. No obstante, las piezas que hasta la fecha sí han podido ser estudiadas enmarcan este conjunto entre los periodos de gobierno de 'Abd al-Rahmān I y al-Hakam I, lo que permite a Martín Escudero (2015: 178) situarlo cronológicamente como perteneciente a los hallazgos de primera época con fechas de cierre pertenecientes al periodo de gobierno de al-Hakam I.

16 Sobre este conjunto hay que matizar que, de los cerca de 200 ejemplares que aparecieron, tan solo pudieron ser estudiados un total de 8, por lo que desconocemos su cronología exacta, si bien, y al igual que sucede con el tesoro de la c/ Doce de Octubre, lo incluimos entre los hallazgos de primera época siguiendo la cuantificación de los conjuntos de dicho periodo realizada por Martín Escudero (2015: 178). 


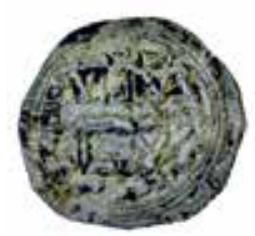

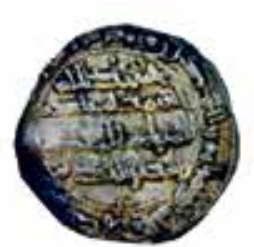

1

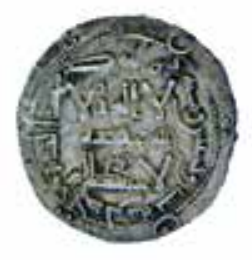

4
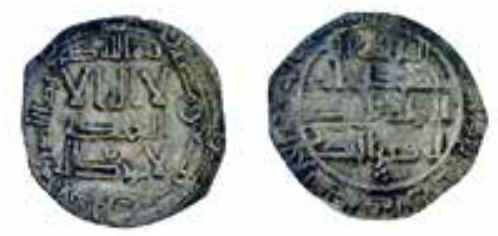

2

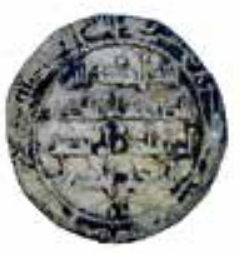

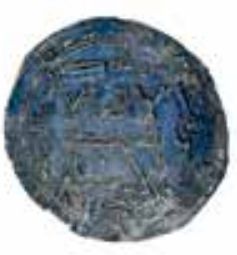

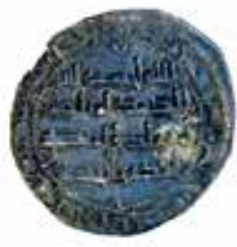

3
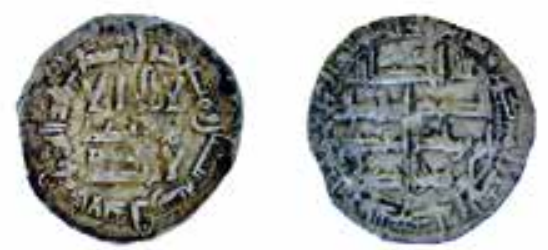

5

FIG. 9. Los dírhams de El Rebollar después de los trabajos de restauración del SECYR.

conjunto objeto del presente estudio, lo que eleva hasta nueve el total de tesorillos de esta cronología (Figs. 8 y 9).

De estos hallazgos, el conjunto de El Rebollar constituye el menos numeroso junto con el localizado en el Cerro de la Almagra, Mula, Murcia, ambos con cinco dirhams ${ }^{17}$. Respecto a su localización geográfica, el hallazgo de El Rebollar es, hasta la fecha, el conjunto más septentrional de todos los conocidos para el gobierno de al-Hakam I.

En lo que se refiere a la composición de los conjuntos anteriormente citados, el tesoro de Córdoba depositado en el man (Canto, 1988: 147-162) consta de 119 monedas que se dividen en dos grandes grupos. El primero de ellos está formado por seis ejemplares pertenecientes a cecas orientales del emirato omeya de Damasco, fechados entre el 90 H./709 d. C. y el 114 H./732 d. C. (Canto, 1988: 147-148). En el segundo grupo, compuesto por ejemplares pertenecientes al periodo del emirato omeya de Córdoba, se han identificado 113 dirhams de ceca al-Andalus que se enmarcan en

17 A pesar de que el número de piezas recuperadas en este yacimiento se eleva a siete, tan solo cinco de ellas aparecieron muy próximas entre sí en el interior de la iglesia (González y Fernández, 2018: 99). una horquilla cronológica que discurre entre 153 H./770 d. C. у 181 н./797-798 d. C. (Canto, 1988: 148-153).

El conjunto Córdoba-calle Doce de Octubre hasta la fecha no ha podido ser clasificado en su totalidad, ya que la mayoría de los ejemplares están pendientes de restauración, por lo que su datación es provisional hasta la catalogación completa del conjunto ${ }^{18}$. Marcos y Vicent (1993: 210-211) indican que estaba formado por 386 dirhams, uno de los cuales fue limpiado y estudiado por M. Ocaña, aportando una fecha del 185 H./801-802 d. C. Posteriormente, Canto (2007a: 18), durante la revisión de los conjuntos depositados en el MAECO, se ocupa de nuevo de este tesorillo indicando que las piezas catalogadas hasta la fecha se enmarcan entre 146 H./763-764 d. C y 188 н./803-804 d. C., es decir, entre los gobiernos de 'Abd al-Rahmān I y al-Hakam I.

El tesorillo de dirhams emirales recuperado en Antequera (Málaga), hallado de manera casual, constaba en origen de 57 monedas, de las que solo 18 fueron estudiadas, si bien los autores del estudio

18 Marcos y Vicent (1993: 210-211) informan de que fue adquirido por indemnización a quien lo localizó y registrado el 3 de septiembre de 1970 en el Museo Arqueológico y Etnográfico de Córdoba con un peso de 1,115 kg. 
indican que este conjunto se clasificó por fechas y fue posteriormente repartido entre sus descubridores de manera equilibrada, por lo que la muestra estudiada puede ser considerada como representativa del total del conjunto. Las fechas de acuñación abarcan una horquilla cronológica entre 154 H./770-771 d. C. y 196 н./811-812 d. C. (Gozalbes y Ayala, 19951996: 235-242).

Del hallazgo de Pinos Puente, Granada, informa Martín Escudero (2011: 121-123) que es un conjunto de 508 dirhams localizado en 1794 contenido en un recipiente cerámico $^{19}$ y con una horquilla cronológica entre $153-200$ H./770816 d. C.

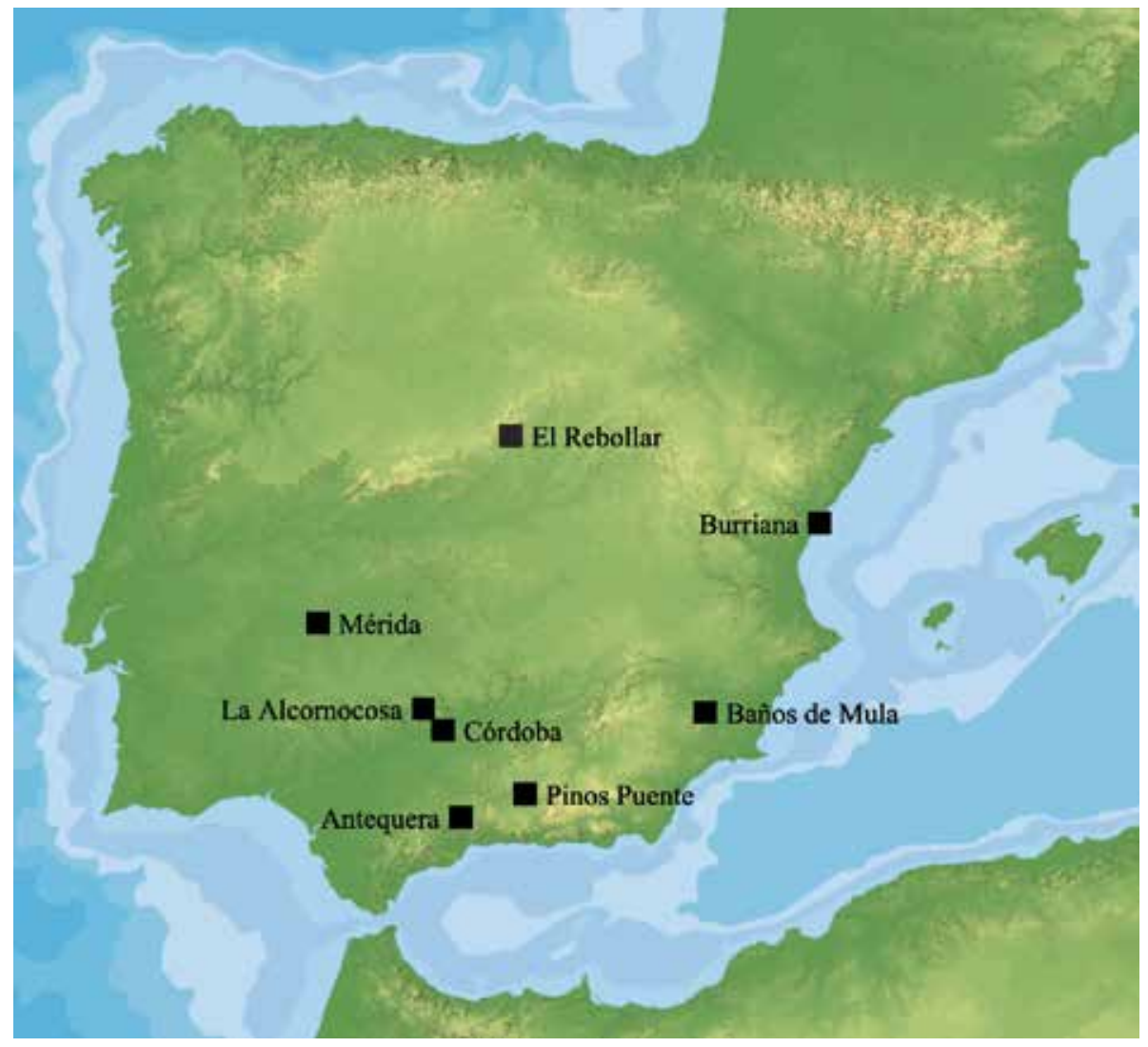

Fig. 10. Mapa de distribución de los hallazgos de la primera época que presentan fechas de cierre en el periodo de al-Hakam I (180-206 H./796-822 d. C.).

En noviembre de 1926, durante una cacería en la finca de La Alcornocosa, en Villaviciosa de Córdoba, se localizaron dos vasijas cerámicas con más de 2.000 monedas de plata, de las cuales casi un millar pasaron a ingresar los fondos del MAECo. Dicho conjunto está formado por dos grandes grupos: 24 monedas del califato omeya de Damasco y dirhams del Emirato Independiente. En este segundo grupo la moneda más antigua se fecha en 147 H./764-765 d. C. y las más modernas fueron batidas en 201 H./816-817 d. C. (Marcos y Vicent, 1993: 194197).

19 Fue estudiado por el intérprete de árabe y bibliotecario de la Real Academia de la Historia Elías Scidiac, a petición de la Junta General de Comercio, Moneda y Minas, quien concluye que se trata de un tesorillo formado por dirhams de los periodos de gobierno de 'Abd al-Rahmān I, Hišām I y al-Ḥakam I.

En el hallazgo de Burriana, Castellón, como ya hemos comentado, del total de monedas recuperadas solo ocho pudieron ser estudiadas, por lo que los datos deben ser tomados con cautela al no conservarse una muestra suficientemente representativa. Las fechas de los dirhams que han sido estudiados se encuadran entre $153 \mathrm{H} . / 770 \mathrm{~d}$. C. y 201 H./816-817 d. C., momento este último al que corresponde el $50 \%$ de los ejemplares (Doménech, 2003: 118-120).

El conjunto Mérida-Teatro Romano, Badajoz, consta de un total de 25 dirhams recuperados durante los trabajos arqueológicos realizados en el teatro romano de Mérida entre 1910 y 1914 y publicados posteriormente por Segovia y Velázquez (2011: 795-816). Las fechas de acuñación de los ejemplares que lo componen comprende una horquilla cronológica que se sitúa entre el año 


\begin{tabular}{|c|c|c|c|c|}
\hline N.o & Depósito & Cronología & Contenedor & Bibliografía \\
\hline 1 & Córdoba en el MAN & $\begin{array}{l}\text { 153-181 н./770- } \\
798 \text { d. C. }\end{array}$ & recipiente cerámico & Canto, 1988: 147-162 \\
\hline 2 & $\begin{array}{l}\text { Córdoba- c/ Doce } \\
\text { de Octubre* }\end{array}$ & $\begin{array}{l}\text { 146-188 н./763- } \\
804 \text { d. C. }\end{array}$ & - & $\begin{array}{l}\text { Marcos y Vicent, 1993: } \\
\text { 210-211; Canto, 2007a: } 18\end{array}$ \\
\hline 3 & Antequera (Málaga) & $\begin{array}{l}154-196 \text { н./ } / 770- \\
812 \text { d. C. }\end{array}$ & ¿contenedor perecedero? & $\begin{array}{l}\text { Gozalbes y Ayala, } \\
\text { 1995-1996: 235-242 }\end{array}$ \\
\hline 4 & $\begin{array}{l}\text { Pinos Puente } \\
\text { (Granada) }\end{array}$ & $\begin{array}{l}153-200 \text { н. } / 770- \\
816 \text { d. C. }\end{array}$ & recipiente cerámico & $\begin{array}{l}\text { Martín Escudero, 2011: } \\
121-123\end{array}$ \\
\hline 5 & $\begin{array}{l}\text { La Alcornocosa } \\
\text { (Villaviciosa de } \\
\text { Córdoba) }\end{array}$ & $\begin{array}{l}\text { 147-201 н./764- } \\
817 \text { d. C. }\end{array}$ & 2 recipientes cerámicos & $\begin{array}{l}\text { Alfaro, 1993: 48; Marcos } \\
\text { y Vicent, 1993: 194-197; } \\
\text { Peńa y Vega, 2007: 147- } \\
\text { 202; Canto, 2007a: } 18-20\end{array}$ \\
\hline 6 & $\begin{array}{l}\text { Burriana } \\
\text { (Castellón)* }\end{array}$ & $\begin{array}{l}153-202 \text { н./770- } \\
817 \text { d. C. }\end{array}$ & - & Doménech, 2003: 118-120 \\
\hline 7 & $\begin{array}{l}\text { El Rebollar } \\
\text { (El Boalo, Madrid) }\end{array}$ & $\begin{array}{l}\text { 195- } 202 \text { H./ } / 810- \\
819 \text { d. C. }\end{array}$ & ¿contenedor perecedero? & inédito \\
\hline 8 & $\begin{array}{l}\text { Mérida-Teatro } \\
\text { Romano (Badajoz) }\end{array}$ & $\begin{array}{l}\text { 190-203 н./805- } \\
819 \text { d. C. }\end{array}$ & ¿contenedor perecedero? & $\begin{array}{l}\text { Segovia y Velázquez, 2011: } \\
795-816\end{array}$ \\
\hline 9 & $\begin{array}{l}\text { Cerro de la Almagra } \\
\text { (Baños de Mula, } \\
\text { Murcia) }\end{array}$ & $\begin{array}{l}206 \text { н./821-822 } \\
\text { d. C. }\end{array}$ & ¿contenedor perecedero? & $\begin{array}{l}\text { González y Fernández, } \\
\text { 2018: 81-119 }\end{array}$ \\
\hline
\end{tabular}

FIG. 11. Conjuntos de monedas fechados en época del emir al-Hakam I (a partir de Martín Escudero, 2015: 197), con modificaciones e indicaciones mediante asterisco de los hallazgos, cuya cronología se considera provisional.

190 H./805-806 d. C. de la pieza más temprana y el 203 H./818-819 d. C. de la más tardía, con mayor porcentaje de ejemplares de los ańos previos al cierre del conjunto. Este pequeño tesorillo no se encontraba asociado a ningún contenedor, lo que incita a pensar a los autores de su estudio en la posibilidad de que se encontrasen en el interior de un objeto de contención perecedero (Segovia y Velázquez, 2011: 803-808).

El más moderno de los conjuntos publicados se documentó en Cerro de la Almagra, en Mula, Murcia. El hallazgo fue localizado durante las excavaciones llevadas a cabo en el interior de una iglesia tardoantigua y consta de un total de cinco dirhams, todos ellos de idéntica cronología: 206 H./821-822 d. C. (González y Fernández, 2010: 99-101).

Además del conjunto de dírhams de El Boalo, también se conocen otros ejemplos de conjuntos monetarios en el interior de espacios religiosos del periodo tardoantiguo en la Península Ibérica. Se trata de los hallazgos, ya mencionados, del Cerro de la Almagra (González et al., 2004; González y Fernández, 2010) y de Reccopoli ${ }^{20}$ (Castro, 2008: 137-139; Castro y Olmo, 2016), si bien este último presenta una fecha de cierre bastante anterior al conjunto recuperado en El Rebollar, así como los ejemplares localizados de manera aislada tanto en la iglesia como en sus alrededores en El Tolmo de Minateda, Hellín, Albacete, fruto de pérdidas casuales (Doménech y Gutiérrez Lloret, 2006; Gutiérrez Lloret y Doménech, 2018).

Así pues, el contexto más parecido al conjunto madrileño es el hallado en Cerro de la Almagra, Baños de Mula, Murcia, pues la mayoría de las monedas, cinco del total de siete recuperadas, se localizaron en el interior de la nave de una iglesia de época tardoantigua (González Fernández y Fernández Matallana, 2018). Al igual que el edificio de culto de El Rebollar, presenta cabecera cuadrangular orientada al este, con dimensiones similares, que también parece corresponder a una iglesia rural (González et al., 2004; González y Fernández, 2018). Al igual que en El Boalo, el conjunto presenta un estado de conservación bastante bueno.

Respecto a la localización geográfica del conjunto monetario de El Rebollar, hay que destacar que, a pesar del escaso número de ejemplares que lo conforman, es el hallazgo de primera época más septentrional de todos los documentados hasta la

20 En este caso el hallazgo se produjo en el paramento interno del muro de cierre que delimita el espacio de la basílica palatina y no en el interior de la iglesia propiamente dicha, si bien, se incluye en este apartado porque técnicamente formaría parte del complejo basilical. 
fecha, en un territorio denominado Al-Tagr al-Awsat, donde el número de hallazgos de dírhams es más bien escaso. Para dicho territorio y, por extensión, para la Meseta Sur, durante todo el periodo emiral solo se constatan los localizados en Reccopoli (Zorita de los Canes, Guadalajara), Sigüenza (Guadalajara) y los dos conjuntos recuperados en Calatrava (Ciudad Real).

De entre los depósitos anteriormente mencionados, el más antiguo cronológicamente hablando es el localizado en Reccopoli. En dicho yacimiento se recuperaron un total de nueve dirhams fechados entre 156 у 169 H./773-786 d. C., es decir, del gobierno de 'Abd al-Rahmān I, que se encontraban ocultos en uno de los paramentos de cierre de la basílica palatina (Castro y Olmo, 2016: 1102-1107). Como los ejemplares localizados en El Rebollar, parece que estas monedas no fueron depositadas en un recipiente cerámico, sino que probablemente también estarían contenidas en algún recipiente de material orgánico, probablemente de tela o cuero.

Sobre el hallazgo de dirhams de Sigüenza se desconoce la fecha de cierre ${ }^{21}$, si bien, la presencia de piezas con hendiduras y grapas permite situarlo entre los denominados 'hallazgos de tercera época', datados durante el gobierno de Muhammad I (Martín Escudero, 2015: 190).

En Calatrava La Vieja, hasta la fecha, se han documentado dos tesorillos diferentes. Sobre el primero de ellos, Alfaro (1993: 53-54) informa de la aparición de un pequeño conjunto de dirhams procedentes del entorno de dicho yacimiento ${ }^{22}$. El

21 Martín Escudero (2011: 292-293) recoge las informaciones aportadas por Ramón Andrés a Pascual de Gayangos y recogidas en el periódico El Conciliador, en el que se da noticia de la aparición en 1845 de un conjunto de "unas cien monedas árabes [...] dentro de una vasija de barro blanco" en las proximidades del municipio de Sigüenza, algunas de las cuales se encuentran "agujereadas con dos incisiones por las que atraviesa una faja del mismo metal [...] que demuestran ser recortaduras de otras monedas semejantes".

22 Depositados en el MAN -n. ${ }^{\circ}$ inv. 1964/65/1, $1964 / 65 / 2,1964 / 65 / 3,1964 / 65 / 4$ y $1964 / 65 / 5-$, se desconocen las circunstancias del hallazgo, del que tan solo consta su acta de depósito en la documentación conservada en el hallazgo estaba compuesto por un total de cinco dirhams emirales de al-Andalus, con fechas de acuñación entre el 192 H./807-808 d. C. y 254 H./868 d. C. Así pues, la acotación cronológica del tesorillo de Calatrava, encuadrada entre los gobiernos de al-Hakam I y Muhammad I, encaja en lo que Martín Escudero (2015: 178-179) denomina 'hallazgos de segunda época', pertenecientes al periodo de gobierno de Muhammad I, y que se definen por fechas de cierre que se dilatan hasta la década de los 50 (García Lerga, 2017: 81-84).

El segundo de los conjuntos documentados en el entorno de Calatrava la Vieja (Ciudad Real) fue recuperado durante la realización de unas obras en las cercanías del yacimiento, en las que se localizó un tesorillo de dírhams emirales en un recipiente cerámico datado en el s. Ix d. C. En su interior se encontraron más de cien dirhams ${ }^{23}$ que se encuadran entre los gobiernos de 'Abd al-Rahmān I y Muhammad I. Tan solo se puede apuntar que, entre las piezas recuperadas en dicho tesorillo, destaca la presencia de moneda de plata carolingia, en concreto, un dinero y varias piezas fragmentadas (Canto, 2002: 115; Martín Escudero, 2013: 342).

De manera más general, para la Meseta Sur también hay que destacar la localización en contextos estratigráficos de hallazgos aislados de dírhams en la Vega Baja de Toledo (García Lerga, 2012: 17-69) y en Segobriga (Abascal et al., 2008: 147), además de las piezas, también aisladas, localizadas en los yacimientos ya mencionados de El Tolmo de Minateda (Doménech y Gutiérrez Lloret, 2005, 2006, 2011; Gutiérrez Lloret y Doménech, 2018) y en Reccopoli (Castro, 2008: 137-139), así como un ejemplar recuperado en el entorno de Atienza durante los trabajos de prospección realizados en el Cerro Padrastro (Valiente y Cuadrado, 1988: 639 y lám. I, 3); todos ellos han sido analizados de forma conjunta en una

\footnotetext{
Museo, en la que se indica que fue donado para su estudio por P. del Arco Ortiz, vecino de Carrión de Calatrava (Ciudad Real), el 25 de abril de 1964.

23 Este conjunto se encuentra actualmente en fase de estudio por A. Canto y M. Retuerce y en breve será objeto de una publicación específica.
} 
monografía de reciente publicación (García Lerga, 2017). Destaca también por su proximidad geográfica con El Boalo el dirham localizado en la dehesa de Navalvillar, en Colmenar Viejo (Colmenarejo, 1987: 51-55). Es un dirham oriental omeya del gobierno de Sulayman, datado en 97 H./715 d. C. del taller de Kirmān (Abad, 2006: 398-399), tipo Klat 529 (Klat, 2002: 199), muy anterior al depósito de El Boalo. Como se puede comprobar, el repertorio de moneda, de momento muy escaso en la región septentrional del distrito toledano, viene a subrayar la importancia del conjunto de El Rebollar.

\section{7. ¿Ocultación o pérdida casual?}

Analizado el conjunto en relación con otros contextos del mismo periodo, podemos plantear si estamos ante una ocultación intencionada o una pérdida casual. En el caso de El Rebollar no nos encontramos con monedas aisladas localizadas en diferentes puntos del yacimiento como sucede en El Tolmo de Minateda (Hellín, Albacete), donde parece a todas luces consecuencia de pérdidas casuales (Doménech y Gutiérrez, 2006; Gutiérrez y Doménech, 2018). El contexto es más semejante al del Cerro de la Almagra (Mula, Murcia), donde se hallaron en el interior de la iglesia tardoantigua cinco dirhams fechados en los años 821-822 d. C. En este caso, también fueron interpretados como pérdida casual y consecuencia de una misma circunstancia, fechando con gran exactitud el último momento de ocupación del yacimiento (González Fernández y Fernández Matallana, 2018: 103).

En el caso de El Rebollar, no se hallaron evidencias de estructuras negativas que pudieran plantear la hipótesis de su ocultación ${ }^{24}$. Aparecen en un

24 Recientemente se ha dado a conocer una ocultación de 239 monedas de plata y fragmentos con fecha de cierre de 270/883-4, en el fondo de un silo de almacenamiento de época islámica en el yacimiento portugués del Cerro da Vila, en Vilamoura, Algarve (Heidemann et al., 2018), aunque se trata de un contexto muy diferente al del conjunto monetario que se da conocer en este trabajo. nivel de la nave de la iglesia que fue reocupado en un momento posterior, dato que hemos confirmado en la excavación arqueológica de 2020 cuando hemos podido continuar la excavación de los pies de la nave y documentar que la antigua iglesia del periodo tardoantiguo no solo se reocupa en el periodo bajomedieval, sino que el edificio duplica su extensión.

El hecho de que se depositaran intencionadamente o se perdieran de forma casual no parece lo más importante, sino que esto se produjo en un edificio que se hallaba en estado de abandono. Conviene recordar que las monedas fueron localizadas entre el nivel más alto de la ocupación de la iglesia tardoantigua y el inicio del derrumbe, como hemos detallado anteriormente. El periodo concreto de la deposición de las monedas no se puede determinar con precisión, pero es bastante probable que se produjera después de su acuñación. De las monedas llama la atención su magnífico estado de conservación, sin apenas desgastes, así como unas fechas de acuñación muy próximas entre sí, con tan solo siete años de diferencia entre el ejemplar más antiguo y el más moderno. En contextos similares, como la iglesia tardoantigua del Cerro de la Almagra (Murcia), las monedas localizadas han permitido plantear un abandono precipitado del yacimiento coincidente con la cronología de las monedas o muy poco después (González Fernández y Fernández Matallana, 2010: 102-103). Las monedas de El Rebollar fueron acuñadas durante la primera mitad del s. Ix d. C., periodo que coincide con el proceso paulatino de desocupación generalizada que se produce en los asentamientos rurales del territorio septentrional del distrito toledano (Vigil-Escalera, 2009: 197). El contexto coincide además con la inestabilidad política derivada del levantamiento de Toledo entre los años 201 y 205 H./816 y 821 d. C. que trajo consigo el refugio de fugitivos procedentes de Córdoba, con el consiguiente aumento de tensión entre la capital de la Marca Media y el emir, llegando este último a enviar a sus tropas a la ciudad (Frochoso, 2009: 62-64).

\footnotetext{
Zephyrus, LXXXVI, julio-diciembre 2020, 239-257
} 


\section{Consideraciones finales}

A modo de conclusión, podemos destacar que el conjunto de dirhams de El Boalo aporta nuevos datos sobre la presencia del numerario islámico en el contexto de la Marca Media, un sector de al-Andalus en el que el número de hallazgos es, en general, más bien escaso. En este sentido, el pequeño conjunto que presentamos, con una cronología que se sitúa entre el 195 y el 202 H./810-818 d. C, aportaría una fecha post quem del 203 H./818-819 d. C., es decir, durante los últimos ańos del periodo de gobierno de al-Hakam I, lo que lo enmarca dentro de los denominados por Martín Escudero (2015: 178) 'hallazgos de primera época'. Esta cronología coincide, en función de los datos obtenidos a partir del análisis estratigráfico, con el abandono del edificio, que en un momento posterior es reocupado y reacondicionado. A tenor de los datos estratigráficos, no podemos confirmar si fueron depositados intencionadamente o perdidos de forma casual, aunque esto debió producirse poco tiempo después de la acuñación de las monedas. En cuanto a la ley de los dirhams de El Rebollar, a pesar de que los porcentajes son algo superiores a la media de las emisiones de al-Ḥakam I de estos años, y si tenemos en cuenta las razones expuestas, pueden considerarse ajustados al patrón medio entre $90-95 \%$ que se establece en los estudios analíticos de las series batidas de dicho periodo.

\section{Bibliografía}

Abad, C. (2006): "El poblado de Navalvillar (Colmenar Viejo)", Zona Arqueológica, 8, pp. 389-399.

Abascal, J. M.; Alberola, A. y Cebrián, R. (2008): Segóbriga IV. Hallazgos monetarios. Madrid: RAH.

Alfaro, C. (1993): "La colección de moneda hispano-árabe del MAN". En III Jarique de Numismática Hispano-Árabe. Madrid: MAN, pp. 39-75.

Alonso, M. A. (1976): "La necrópolis del Cerro de las Losas en el Espartal (Madrid)", Noticiario Arqueológico Hispánico, 4, pp. 287-323.

Aracil, E.; Maruri, U.; Gómez Osuna, R.; Colmenarejo, F.; Pozuelo, A.; Rovira, C. y Jiménez
Guijarro, J. (2016): "Dos enclaves minero-metalúrgicos durante la Antigüedad Tardía en el centro de la Península: Navalvillar y Navalahija (Colmenar Viejo)". En Reunión de Arqueología Madrileña, 2014. Alcalá de Henares: Colegio de Arqueólogos de Madrid-Dir. Gral. de Patrimonio Cultural de la Com. de Madrid, pp. 247-256.

ArandA, R. (2013): "Una aportación al conocimiento de las producciones cerámicas de época visigoda: el conjunto cerámico de la parcela R3 de la Vega Baja (Toledo)". Espacio, Tiempo y Forma. Serie I. Prehistoria y Arqueología, 6, pp. 381-450. doi: https://doi. org/10.5944/etfi.6.2013.11893.

Blázquez, C. y Martín Esquivel, A. (2019): "Conjunto de dírhams califales hallado en Zamora. Estudio e interpretación”, Archivo Español de Arqueología, 92, pp. 287-306.

Caballero, L. y Megías, G. (1977): "El Cancho del Confesionario", Noticiario Arqueológico Hispánico, 5, pp. 325-331.

Camps, E. (1984; 4. ${ }^{a}$ ed.): "El arte hispanovisigodo". En Menéndez Pidal, R. (coord.): Historia de España, vol. 3. Madrid: Prensa de la Univ. de Madrid, 1970, pp. 491-830.

Canto, A. (1988): "Tesoro de moneda emiral del siglo II de la Hégira conservado en el MAN". En I Jarique de Estudios Numismáticos Hispano-árabes. Zaragoza: Instit. Fernando el Católico, pp. 147-162.

Canto, A. (1994): "De contenidos metálicos en la moneda hispano-árabe de época omeya". En Anaquel de Estudios Árabes. Madrid: UCM, pp. 129-137.

Canto, A. (2002): "Moneda foránea en al-Andalus". En $x$ Congreso Nacional de Numismática (Albacete, 1998). Madrid. pp. 107-128.

Canto, A. (2007a): "Tesoro de la calle 12 de octubre". En Maskukat. Tesoros de monedas andalusies en el Museo Arqueológico de Córdoba. Catálogo de la exposición (Córdoba, 2007). Córdoba: Consejería de Cultura, p. 18.

Canto, A. (2007b): "Las monedas y la conquista", Zona Arqueológica, 15 (1), pp. 135-146.

Canto, A. е IвrĀHĪm, T. (2004): Moneda andalusí. La colección del Museo Casa de la Moneda. Madrid: Fundac. Casa de la Moneda.

Canto, A. y Marsal, E. (1986): "On the metrology of the silver coinage of the Spanish Amirate". En MARQues, M. G. (ed.): Problems of Medieval Coinage in the Iberian Area 2. Avilés: Instituto Politécnico de Santarém, pp. 167-180. 
CASTRO, M. (2000): "Una nueva aproximación a las emisiones del Emirato Independiente (138-316/755(6)928 d. C.) y su alcance social", Arqueología y Territorio Medieval, 7, pp. 171-184.

Castro, M. (2008): "Los hallazgos numismáticos de Recópolis: aspectos singulares de su integración en la secuencia histórica del yacimiento". En Olmo, L. (ed.): Recópolis y la ciudad en la época visigoda. Zona Arqueológica, 9. Alcalá de Henares: MAR, pp. 130-141.

Castro, M. y Olmo, L. (2016): "Dírhams, feluses y contextualización arqueológica en el centro de la Península: nuevos hallazgos de época emiral (ss. VIII-IX d. C.) en Recópolis". En Grañeda, P. (ed.): Patrimonio numismático y museos. Actas XV Congreso Nacional de Numismática. Madrid: Museo Casa de la Moneda, pp. 1097-1114.

Colmenarejo, F. (1987): Arqueología medieval de Colmenar Viejo. Colmenar Viejo: Ayto. de Colmenar Viejo.

Colmenarejo, F. (2009): "Piedras, piquetas y pinceles: en busca de la Antigüedad Tardía en Navalahija, dehesa de Navalvillar, Colmenar Viejo", Cuadernos de Estudios: Revista de Investigación de la Asociación Cultural 'Pico San Pedro', 23, pp. 69-97.

Colmenarejo, F.; Gómez Osuna, R.; Pozuelo, A.; Rovira, C.; García Aragón, E.; Jiménez Guijarro, J. y Fernández Suárez, R. (2016): "Poblamiento durante la Antigüedad Tardía y la Edad Media en la presierra madrileña: Cuenca Alta del Manzanares". En Reunión de Arqueología Madrileña 2014. Alcalá de Henares: Colegio de Arqueólogos de Madrid-Dir. Gral. de Patrimonio Cultural de la Com. de Madrid, pp. 277-286.

Colmenarejo, F. y Rovira, C. (2006): "Los yacimientos arqueológicos de Colmenar Viejo durante la Antigüedad tardía”, Zona Arqueológica, 8 (2), pp. 377-388.

Colmenarejo, F.; Rovira, C.; Pérez Martín, S. y ANTONA, A. M. (2005): Guía del yacimiento arqueológico de Remedios, un cementerio rural durante la antigüedad tardía (siglo VII d. C.). Colmenar Viejo.

Doménech, C. (2003): Dinares, dirhames y feluses: circulación monetaria islámica en el País Valenciano. Alicante: Univ. de Alicante.

Doménech, C. y Gutiérrez Lloret, S. (2005): "Las monedas de El Tolmo de Minateda (Hellín, Albacete)". En XIII Congreso Internacional de Numismática. Madrid: Ministerio de Cultura, pp. 1567-1576.

Doménech, C. y Gutiérrez Lloret, S. (2006): “Viejas y nuevas monedas en la ciudad emiral de Madinat
Iyyuh (El Tolmo de Minateda, Hellín, Albacete)", $A l$ Qantara, 27 (2), pp. 337-334.

Doménech, C. y GuTiÉrRez Lloret, S. (2011): "Monedas en contexto. La ciudad altomedieval de El Tolmo de Minateda (Hellín, Albacete, España)”. En Pardini, G.; Parise, N. y Marani, F. (eds.): Numismatica e Archeologia. Monete, Stratigrafie e Contesti. Dati a confronto. Roma: Quasar, pp. 64-67.

Fernández Galiano, D. (1976): "Excavaciones en la necrópolis hispano-visigoda del Camino de los Afligidos (Alcalá de Henares)", Noticiario Arqueológico Hispánico, 4, pp. 1-71.

Fernández Ruiz, R.; Salvador, E. y Canto, A. (2001): "Evolución de la ley $(\mathrm{Ag} / \mathrm{Cu})$ en monedas árabes durante los siglos VII al $\mathrm{x}$ d. C. mediante SEM-EDX y txrf". En Gómez Tubío, B.; Respaldiza, M. A. y Pardo, M. L. (eds.): III Congreso Nacional de Arqueometría. Sevilla: Univ. de Sevilla-Fundac. El Monte, pp. 563-570.

Frochoso, R. (2009): El dirham andalusí en el Emirato de Córdoba. Bibliotheca Numismática Hispana, 7. Madrid: RAH.

García Lerga, R. L. (2012): "Hallazgos monetarios de época emiral en la Vega Baja de Toledo", Gaceta Numismática, 183, pp. 17-69.

García Lerga, R. L. (2016): "La moneda emiral en la Meseta Sur. Un estado de la cuestión”. En GrañEda, P. (ed.): Patrimonio numismático y museos. Actas XV Congreso Nacional de Numismática. Madrid: Museo Casa de la Moneda, pp. 1115-1132.

GarCía LeRGA, R. L. (2017): El cambio de patrón monetario en la Meseta Sur durante la formación al-Andalus (92-316 H./711-929 d. C.). Montpellier: OMNI.

Gisbert, J. A. (1986): "Las cerámicas de cronología visigoda en las necrópolis del País Valenciano". En Zozaya, J. (coord.): II Coloquio Intern. de Cerámica Medieval en el Mediterráneo Occidental. Madrid, pp. 207-215.

Gómez Osuna, R.; García Aragón, E.; Colmenarejo, F. y Pozuelo; A. (2018): "Enterramientos infantiles altomedievales en La Cabilda: Hoyo de Manzanares, Madrid", Territorio, Sociedad y Poder: Revista de Estudios Medievales, 13, pp. 22-47.

González Fernández, R. y Fernández Matallana, F. (2018): "Mula: el final de una ciudad de la cora del Tudmîr", Pyrenae, 41-42, pp. 81-119.

Gómez Osuna, R.; García Aragón, E.; Pozuelo, A.; Colmenarejo, F. y Fernández Suárez, R. (2016): "El yacimiento arqueológico de La Cabilda (Hoyo de Manzanares): una aldea del siglo viI d. C. al pie de la 
Sierra de Guadarrama”, Cuadernos de Estudios: Revista de Investigación de la Asociación Cultural 'Pico San Pedro', 30, pp. 43-65.

González Fernández, R.; Fernández Matallana, F. y Crespo, M. S. (2004): "La necrópolis intramuros con edificio de culto del Cerro de La Almagra (Mula, Murcia)", Memorias de Arqueología, 13, pp. 265-276.

Gozalbes, C. y Ayala, J. A. (1995-1996): "Un tesorillo de monedas del emirato independiente hallado en el Cerro de la Fuensanta (Antequera-Casabermeja-Colmenar. Málaga)", Mainake, XVII-XvıII, pp. 235-242.

Gutiérrez Lloret, S. (1996): La Cora de Tudmir: de la Antigüedad Tardía al Mundo Islámico. Poblamiento y cultura material. Madrid.

Gutiérrez Lloret, S. y Doménech, C. (2018): “Coinage, context and social space. The high medieval city of El Tolmo de Minateda (Hellín, Albacete, Spain)". En Pardini, G.; Parise, N. y Marani, F. (eds.): $N u$ mismatica e Archeologia. Monete, Stratigrafie e Contesti. Dati a confronto. Roma: Quasar, pp. 487-500.

Gutiérrez Lloret, S.; Gamo, B. y Amorós, V. (2003): "Los contextos cerámicos altomedievales del Tolmo de Minateda y la cerámica altomedieval en el sudeste de la Península Ibérica”. En Caballero, L.; Mateos, P. y Retuerce, M. (eds.): Cerámicas tardorromanas y altomedievales en la Península Ibérica. Ruptura y continuidad. Anejos de Archivo Español de Arqueología, XXVIII. Madrid: CSIC, pp. 119-168.

Heidemann, S.; Schierl, T. y Teichner, F. (2018): "Coins from the seaside. An Emiral silver coin hoard from a harbour settlement on the Cerro de Vila (Vilamoura, Algarve, Portugal)", Al-Qantara, xxxix (1), pp. 169-224.

Juan, E. e Centelles, I. (1985): "El yacimiento de época visigoda del Plà de Nadal (Riba-Roja de Turia, Camp de Turia: Valencia)". En Actas I Congreso de Arqueología Medieval Española. Huesca, vol. 2, t. 2 pp. 25-40.

KLat, M. G. (2002): Catalogue of the Post-Reform Dirhams. The Umayyad Dynasty. London: Spink \& Son.

Marcos, A. y Vicent, A. M. (1993): "Los tesorillos de moneda hispano-árabe del Museo Arqueológico de Córdoba". En III Jarique de Numismática Hispano-Árabe. Madrid: MAN, pp. 183-218.

Martín Escudero, F. (2005a): El Tesoro de Baena. Madrid: RAH.

Martín Escudero, F. (2005b): "Hallazgos de dírhames omeyas: estudio e interpretación”. En Alfaro, C.; Marcos, C. y Otero, P. (eds.): XiII Congreso
Internacional de Numismática. Madrid: Ministerio de Cultura-INC-MAN, t. 2, pp. 1615-1624.

Martín Escudero, F. (2011): Las Monedas de al-Andalus. De actividad ilustrada a disciplina científica. Madrid: RAH.

Martín Escudero, F. (2013): "Monedas que van... monedas que vienen. Circulación monetaria en época de cambios". En De Mahoma a Carlomagno. Los primeros tiempos (siglos VII-IX). Pamplona: Gob. de Navarra, pp. 311-350.

Martín Escudero, F. (2015): “Tesoros numismáticos. Mucho más que monedas acumuladas. Hallazgos monetarios de los Emiratos Dependiente e Independiente". En Lafaurie, J. y Pilet-Lemière, J. (eds.): Monnaies du Haut Moyen Âge: histoire et archéologie (Péninsule Ibérique-Maghreb, VII -XI siècle). París: CNRS, pp. 173-210.

Martín Viso, I. (2002): "Espacio y poder en los territorios serranos de la Región de Madrid (siglos X-XIII)", Arqueología y Territorio Medieval, 9, pp. 53-84.

Medina, A. (1992): Monedas hispano-musulmanas: manual de literatura y clasificación. Toledo: Instituto Provincial de Investigaciones y Estudios Toledanos.

Méndez, A. y Rascón, S. (1989): Los visigodos en Alcalá de Henares. Cuadernos del Juncal, 1. Alcalá de Henares: Banco del Comercio.

Pellicer i Bru, J. (2015): "L'enigma de les monedes cisades. Estudi de 120 peces emirals andalusines Arroyo de la Luz (Cáceres)". En XXVII Encuentro de Estudios sobre la Moneda. Ponencias. Gaceta Numismática, 189. Barcelona: ANE, pp. 3-40.

Peña, S.yVega, M. (2007): “Laamonedación canónicadel emirato omeya andalusí antes de 'Abd al-Rahmān II, según el hallazgo de dírhams de Villaviciosa (Córdoba)". Al-Andalus-Magreb: Estudios Árabes e Islámicos, 14, pp. 149-202.

Rojas, J. M.; Vicente, A. y Eger, C. (2018): "La basílica de Guarrazar desde los hallazgos arqueológicos". En X Jornadas Visigodas. Guadamur: Ayto. de Guadamur, pp. 57-86.

Salvador, E. y Canto, A. (2004): "Informe sobre la técnica utilizada de análisis por Energía Dispersiva de Rayos X". En Canto, A. e IвrĀHĪm, T. (2004): Moneda andalusí. La colección del Museo Casa de la Moneda. Madrid: Fundación Casa de la Moneda, Apénd. 1, pp. 117-119.

Sanguino, J. y Oñate, P. (2016): "Actuaciones arqueológicas en la ermita de San Babilés (Boadilla del Monte)". En Reunión de Arqueología Madrileña, 
2014. Alcalá de Henares: Colegio de Arqueólogos de Madrid, pp. 237-246.

Segovia, R. y Velázquez, A. (2011): "Un inédito tesorillo de moneda emiral independiente hallado en el Teatro Romano de Mérida". En Actas XIV Congreso Nacional de Numismática: Ars metallica, monedas $y$ medallas. Madrid: Museo Casa de la Moneda, pp. 795-816.

Valiente, J. y Cuadrado, M. A. (1988): "Las Torres de Atienza”. En Actas I Encuentro de Historiadores del Valle del Henares (Guadalajara, 1988). Guadalajara: Institución de Estudios Complutenses, pp. 631-642.
Vigil-Escalera, A. (2009): "Sepulturas, huertos y radiocarbono (siglos viII-XIII d. C.). El proceso de islamización en el medio rural del centro peninsular y otras cuestiones", Studia Historica. Historia Medieval, 27, pp. 97-118.

Vigil-Escalera, A. (2011): "Formas de poblamiento rural en torno al 711 documentación arqueológica del centro peninsular", Zona Arqueológica, 15, pp. 189-204.

Vives y Escudero, A. ([1893]; edic. 1998): Monedas de las dinastías arábigo-españolas. Madrid: Fund. Fomento Estudios Numismáticos, 2 vols. 